\title{
Design, Development and Test of 2m Quadrupole Model Magnets for the LHC Inner Triplet
}

J. Kerby, A.V. Zlobin, R. Bossert, J. Brandt, J. Carson, D. Chichili, J. Dimarco, S. Feher, M.J. Lamm, P.J. Limon, A. Makarov, F. Nobrega, I. Novitski, D. Orris, J.P. Ozelis, B. Robotham, G. Sabbi, P. Schlabach, J.B. Strait, M. Tartaglia, J.C. Tompkins, Fermi National Accelerator Laboratory, Batavia, Illinois, USA

S. Caspi, A.D. McInturff, R. Scanlan, Lawrence Berkeley National Laboratory, Berkeley, California, USA

\begin{abstract}
Fermilab and LBNL are in the midst of a model magnet program to develop and prove the design of quadrupoles for use in the LHC Interaction Region inner triplets. These magnets have a nominal gradient of $205 \mathrm{~T} / \mathrm{m}$ in a $70 \mathrm{~mm}$ bore, and operate in superfluid helium at $1.9 \mathrm{~K}$. The R\&D program addresses magnetic, mechanical, thermal design and quench protection issues. This paper describes design, fabrication experience and test results from the first $2 \mathrm{~m}$ models.
\end{abstract}

\section{INTRODUCTION}

The final focus in the LHC low- $\beta$ insertions is achieved with inner quadrupole triplets, each consisting of four $70 \mathrm{~mm}$ single aperture superconducting quadrupoles (MQX) connected in series [1]. Besides accommodating two fully separated beams at injection, the MQX magnets must provide a high field gradient and low multipole errors required for the collision optics of the proton beams, while absorbing on the order of $160 \mathrm{~W}$ of energy at $1.9 \mathrm{~K}$ from the secondary particles generated. A quadrupole based on these requirements is being developed in the U.S. for two of the four LHC interaction regions, with KEK developing the quadrupoles for the other interaction points [2].

The $R \& D$ program started last year, and includes the fabrication of a set of model magnets (HGQ) to study and optimize the magnet design features, including cable optimization, insulation design, mechanical support, inner to outer layer splice design, end design, end part materials, quench protection and heater design, and field quality. A pair of HGQ models will then be fabricated utilizing the final design to study the reproducibility of the magnet parameters, before proceeding to a full length MQX prototype. This paper reviews the current fabrication experience, the test results of the first two HGQ models, and the preliminary results of the third model magnet which is currently being tested.

\section{MAGNet Design}

The HGQ cross-section is shown in Figure 1. Each of the four coils consists of 14 turns in the inner layer, and 16 turns in the outer, with two copper wedges, one in each layer, to

Manuscript received September 15, 1998.

Work supported by the U.S. Department of Energy adjust the field quality in magnet straight section. The coil ends retain the block-wise layout of turns, which have been optimized to reduce the peak field and improve the field quality.

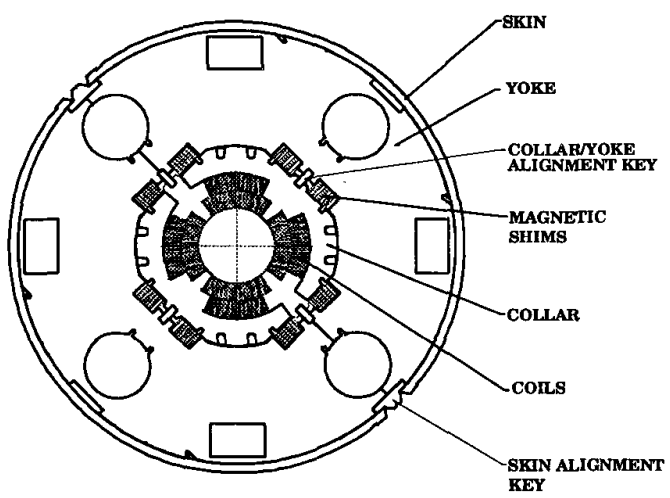

Fig. 1. High Gradient Quadrupole cross-section.

Both layers are made of keystoned Rutherford-type superconducting cables utilizing SSC strand. The inner layer cable consists of $380.808 \mathrm{~mm}$ strands and has a cross section with a minor edge of $1.326 \mathrm{~mm}$, a major edge of $1.587 \mathrm{~mm}$ and a width of $15.4 \mathrm{~mm}$. The outer layer cable consists of $460.648 \mathrm{~mm}$ strands and has a $1.054 \mathrm{~mm}$ minor edge, a $1.238 \mathrm{~mm}$ major edge and the same width of 15.4 $\mathrm{mm}$. Both cables have a packing factor of $91 \%$. The NbTi filament size in the strands of both layers is $6 \mu \mathrm{m}$, and the $\mathrm{Cu}: \mathrm{Sc}$ ratio is $1.3: 1$ for inner strand and 1.8:1 for the outer strand. The strand critical current density at $5 \mathrm{~T}$ and $4.2 \mathrm{~K}$ is greater than $2.75 \mathrm{kA} / \mathrm{mm}^{2}$.

The inner and outer cables are insulated using two wraps. The inner wrap for both cables is made of Kapton film 25 $\mu \mathrm{m}$ thick and $9.5 \mathrm{~mm}$ wide wound with $50 \%$ overlap. The outer wrap of inner cable is made of $50 \mu \mathrm{m}$ thick Kapton film wound with a $2 \mathrm{~mm}$ gap, while the outer cable outer wrap consists of Kapton film $25 \mu \mathrm{m}$ thick and $9.5 \mathrm{~mm}$ wide with $50 \%$ overlap. The gaps in the outer wrap of the inner cable significantly increase the wetted perimeter and allow for Hell penetration, enhancing the removal of energy deposited in the inner coil [3]. 
The HGQ coil prestress is provided by freestanding Nitronic 40 collars, with a target coil prestress for both the inner and outer coils at $300 \mathrm{~K}$ is between 70 and $85 \mathrm{MPa}$. The collars are assembled by hand, alternating between poles, and locked in place by two stainless steel keys at each of 4 locations around the circumference. The collars have an arc length of less than $180^{\circ}$, such that when assembled every other pole is left as a HeII heat conduction path from the coil, through the collar region, to cooling holes in iron yoke [4]. The collar width in the key regions has been increased from 20 to $25 \mathrm{~mm}$ to allow margin for stress concentrations near the collar keys.

Prestress and mechanical support of the return end of the magnet is provided by full round collars, which are body collars with the pole section removed such that space is created to accept the end parts. At the lead end, two systems have been tested, depending on the design of the inner to outer layer splice. For external splice magnets, HGQ01 and HGQ02, support is provided by a $30 \mathrm{~mm}$ thick aluminum end can, clamping end blocks which support the inner to outer layer splice in each quadrant and the coil ends on their inner radius. For the internal splice used in HGQ03, full round collars as on the return end of the magnet are used. Coil end parts have been made of two materials, G10 in HGQ01 and Ultem in HGQ02 and HGQ03.

The assembled collared coil is centered inside the two piece iron yoke by alignment keys, located at the pole of each quadrant. The yoke inner radius is $92.56 \mathrm{~mm}$, which allows for a $350 \mu \mathrm{m}$ gap between collar and yoke laminations radii at the key region. The outer radius of the yoke laminations is $200 \mathrm{~mm}$. The current yoke laminations feature four round holes for the HeII heat exchange and four rectangular holes for electrical connections. Both of these features will be optimized in the final design. In the pole regions, eight rectangular gaps between collar and yoke house the magnetic tuning shims used for field quality correction. To increase the operating margin in the coil ends, the iron yoke is terminated at a distance of $100 \mathrm{~mm}$ from the lead end of the coil straight section and $50 \mathrm{~mm}$ from the return end, being replaced with stainless steel laminations of the same design.

The iron yoke is surrounded by an $8 \mathrm{~mm}$ thick stainless steel skin. Skin alignment keys provide for longitudinal alignment, as well as the weld geometry for the closure of the vessel. Two $50 \mathrm{~mm}$ thick stainless steel end plates welded onto the skin are available for the application of longitudinal preload to the coil quadrants through end bullets. The quadrant splice assembly is mounted on the outer surface of the lead end plate.

\section{MAGNET FABRICATION}

Superconducting Cable. Approximately $2 \mathrm{~km}$ each of inner and outer cable have now been produced by LBNL. Inner cable has been produced using both right and left lays, and both have been successfully wound and cured. The use of left lay cable would allow for the utilization of existing SSC inner strand with the right lay twist. The cable produced meets the size requirements, though a small modification to the cable thickness may be incorporated in the final design to help achieve the desired cured coil size. Critical current measurements done at BNL show the strand critical current degradation after cabling does not exceed 3-4\%.

Mechanical Model. Three $0.4 \mathrm{~m}$ long mechanical models have been made whose primary purpose was to validate the finite element modeling and determine the appropriate coil shims to yield a nominal inner/outer collared coil prestress. The models were instrumented with beam and capacitance gauges to measure inner and outer coil stresses. Based on this study, it was determined that target coil sizes of $250 \mu \mathrm{m}$ and $375 \mu \mathrm{m}$ were needed to achieve a pretress of $84 \mathrm{MPa}$ in the inner and outer coils, respectively.

Magnet Coil. 34 inner and 28 outer coils with G-10 and Ultem end parts have been wound, cured and measured [5]. The RMS spread of azimuthal size for each coil is within $\pm 15 \mu \mathrm{m}$, and the difference in the average coil size of the 4 coils used in HGQ01 was $\pm 50 \mu \mathrm{m}$, with subsequent sets improving. The evolution of coil size for coils used in or designated for HGQ01 through HGQ04 is shown in Figure 2 , and the effect of changes in the curing cavity size and minor modifications of the insulation scheme are apparent. Typical measurements of the modulus for increasing stress are $5 \mathrm{GPa}$ for inner coils and $10 \mathrm{GPa}$ for outer coils.

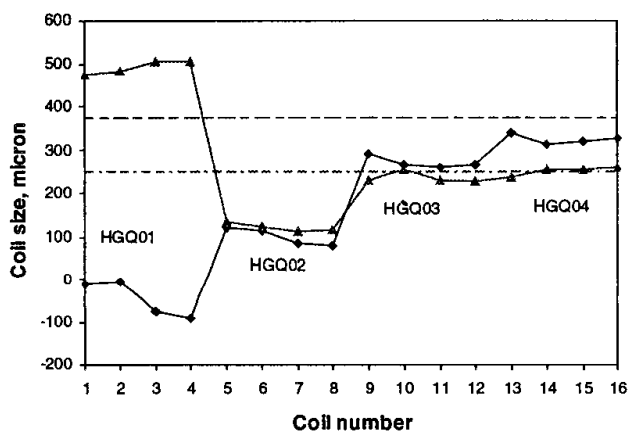

Fig. 2. Inner (diamond) and outer (triangle) coil size with respect to master block measured at $84 \mathrm{MPa}$. The upper line represents the target size for the inner coil, the lower line the target for the outer coil. Values above the nominal line indicate oversized coils.

Collared Coil. The first three HGQ models have been assembled, collared, and instrumented with 120 voltage taps, 8 beam gauges, and 4 capacitance gauges each.

Three turn-to-turn shorts were discovered during the assembly of HGQ01: one in the body of the quadrant 1 inner coil near the return end, a second in the quadrant 3 inner coil near the tip of the lead end saddle, and a third in the quadrant 3 inner coil in the lead end near a voltage tap. Each of these shorts was repaired during construction. To decrease the possibility of turn-to-turn shorts in subsequent magnets the voltage tap assembly procedure was modified, and fixtures were made to azimuthally press the end of each coil before 
assembly to the pressures incurred during the keying operation. There has only been one short, in the end of an inner coil, found since the introduction of the inspection procedure, and this coil was set aside and replaced with another such that collaring of this magnet could proceed successfully without repairs during construction.

Cold Mass. Final assembly of the cold mass occurs as the collared coil is inserted into the iron yoke and the skin welded. Model HGQ01 showed considerable buckling of the yoke laminations at the lead and return ends, which has been addressed by increasing the width of the skin alignment key, and adding several fusion passes to the end yoke packs in magnets $\mathrm{HGQO2}$ and HGQ03.

For the initial test of HGQ01, a low end preload of $1.5 \mathrm{kN}$ per quadrant was applied due to the shorts seen during fabrication. After the first test, each of the return end bullets were tightened to $26.7 \mathrm{kN}$. The lead end bullets are not readily accessible, since they are covered by the quadrant splice block. However, since the collared coil is free to move within the yoke, applying load at the return end increased the load on each lead end bullet to $13.3 \mathrm{kN}$. For initial tests of HGQ02, each bullet was torqued to $13.3 \mathrm{kN}$ on the return end, with a lead end load was $8.9 \mathrm{kN}$ per bullet. For the second thermal cycle, the return end bullet load was removed. As these changes resulted in no change in the magnet quench performance, $\mathrm{HGQ03}$ was initially assembled with no longitudinal load applied at the ends.

\section{TEST RESUlts}

Mechanical Measurements. The strain gauges installed in magnet straight section and ends record the coil prestress after collaring, after cooldown, and during excitation. Measurement results and design values [6] are summarized in Table I. HGQ03 data is not included as the magnet is currently under test and the analysis is not complete.

Table I

MECHANICAL MEASUREMENT SUMMARY

\begin{tabular}{|l|l|l|l|l|}
\hline & Unit & Design & HGQ01 & HGQ02 \\
\hline $\begin{array}{l}\text { Azimuthal } \\
\text { prestress 300K } \\
\text { - inner layer }\end{array}$ & & & & \\
- outer layer & $\mathrm{MPa}$ & $81 \pm 12$ & $67 \pm 21$ & $73 \pm 17$ \\
\hline Cool down & & $81 \pm 20$ & $72 \pm 18$ & $94 \pm 15$ \\
loss & & & & \\
- inner layer & $\mathrm{MPa}$ & 7 & -29 & +3 \\
- outer layer & $\mathrm{MPa}$ & 15 & -14 & -10 \\
\hline Azimuthal & & & & \\
Lorentz force & & & & \\
- inner layer & $\mathrm{MPa} / \mathrm{kA}^{2}$ & -0.3 & -0.28 & -0.31 \\
- outer layer & $\mathrm{MPa} / \mathrm{kA}^{2}$ & -0.2 & -0.13 & -0.15 \\
\hline longitudinal & & & & \\
Lorentz force & & & & \\
- lead end & $\mathrm{kN} / \mathrm{kA}^{2}$ & 0.36 & 0.09 & 0.08 \\
- return end & $\mathrm{kN} / \mathrm{kA}^{2}$ & 0.36 & 0.09 & 0.07 \\
\hline
\end{tabular}

Agreement between the azimuthal values is reasonable, and shows the coil prestress to be sufficient in the body for operation. In the longitudinal direction, only during the second thermal cycle of HGQ01 was contact maintained at all times between the coil ends and the end plate. In all other cycles, contact was achieved between the coil end and the end plate only at significant currents. The measured Lorentz force reported in Table I reflects the slope of the bullet strain gauge readings only after contact is made between the coil ends and the bullets. Note that only about $25 \%$ of the calculated Lorentz force is developed in the bullets.

Quench Performance. Figure 3 summarizes the quench performance of the first three HGQ models leading up to the first thermal cycles at $1.9 \mathrm{~K}$.

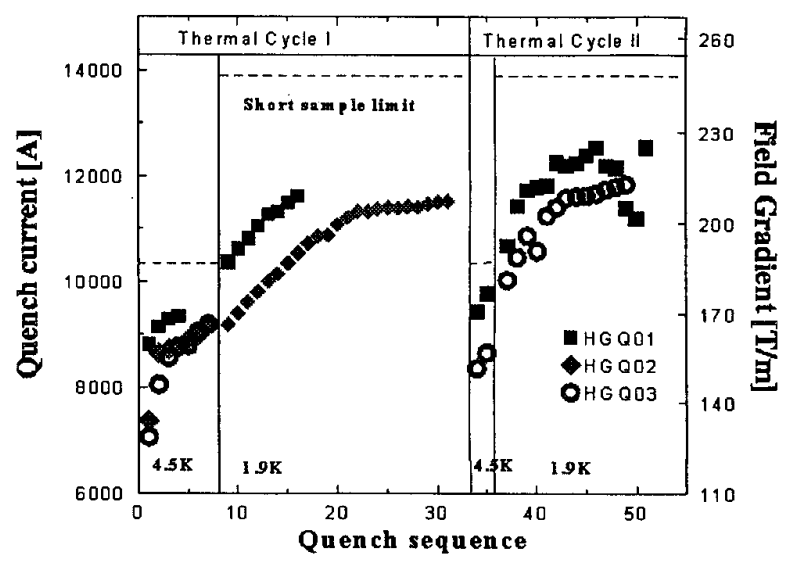

Fig. 3. Magnet training summary.

The performance of HGQ01 was dominated by quenches in the ends and the body/end transition. The transition region from the body to the end had several problems, driven by oversizing of the outer coil and the voltage tap placement [7]. The long training of HGQ02 is defined by multiple quenches at a single location in an inner coil, after which a plateau is achieved where quenches occur in similar locations in other quadrants. The end quenches are currently attributed to insufficient azimuthal end prestress in the inner coil and poor adhesion of the end parts to the cured coil. The specific location at which many of the training quenches occurred will be inspected upon the disassembly of the magnet. In neither of these magnets did the change in longitudinal coil load affect quench performance. HGQ03 is currently undergoing testing, but preliminary indications are that the quenches are located dominantly in the transition regions. For all magnets, the ramp rate sensitivity is low. The temperature margin at nominal current is more than 2.3 $\mathrm{K}$ and it is in a good agreement with the calculations.

Quench Protection. Inter layer and outer layer quench heaters have been installed and tested in magnets HGQ01 and HGQ02 [8]. Both the inter and outer heaters are capable of initiating quenches above $2.5 \mathrm{kA}$ with acceptable values of power supply voltage and heater time delay. A new heater design with longitudinally distributed resistance is being studied in HGQ03 which should further reduce the heater power supply consumption and voltage. 
Spot heaters have been used to induce quenches in selected parts of the magnet coil. Using either the inter or the outer quench heaters for protection, the maximum quench integral from these quenches does not exceed 19 MIITs which corresponds to less than a $200 \mathrm{~K}$ peak temperature in the inner coil. The quench protection of the outer coil requires further study and is included in the ongoing test program. The spot heater studies also show that the peak coil voltage will not exceed $200 \mathrm{~V}$ for the full scale magnets.

Magnetic Measurements. The transfer function (G/I) measured for the models at low currents is $18.35 \mathrm{~T} / \mathrm{m} / \mathrm{kA}$, with iron saturation reducing the value by $2 \%$ at the nominal operating current of $11.5 \mathrm{kA}$. Field harmonics at reference radius $17 \mathrm{~mm}$ in the body of the magnet measured at $6 \mathrm{kA}$ [9] are summarized in Table II, along with the uncertainty in the systematic values and RMS spread expected for the MQX magnets [10].

Table II

FIELD HARMONICS SUMMARY

\begin{tabular}{|c|c|c|c|c|c|c|c|c|}
\hline $\begin{array}{c}\text { Har- } \\
\text { monic }\end{array}$ & Error tables & \multicolumn{2}{|c|}{ HGQ01 } & \multicolumn{2}{c|}{ HGQ02 } & \multicolumn{2}{|c|}{ HGQ03 } \\
\cline { 2 - 10 } & Delta & Sigma & Meas. & Calc. & Meas. & Calc. & Meas. & Calc. \\
\hline b3 & 0.34 & 0.85 & 0.36 & 0 & -0.70 & 0 & 1.04 & 0 \\
\hline a3 & 0.34 & 0.85 & 0.27 & 0 & 0.55 & 0 & -0.30 & 0 \\
\hline b4 & 0.26 & 0.87 & 0.26 & 0 & 0.18 & 0 & 0.14 & 0 \\
\hline a4 & 0.26 & 0.87 & 2.00 & 1.27 & 0.53 & 0.94 & 0.32 & 0 \\
\hline b5 & 0.2 & 0.34 & -0.29 & 0 & 0.09 & 0 & -0.34 & 0 \\
\hline a5 & 0.2 & 0.34 & 0.02 & 0 & -0.17 & 0 & 0.26 & 0 \\
\hline b6 & 0.17 & 0.25 & -3.91 & -4.24 & -1.54 & -2.86 & -1.02 & -1.39 \\
\hline a6 & 0.17 & 0.25 & -0.018 & 0 & 0.03 & 0 & 0.07 & 0 \\
\hline b7 & 0.14 & 0.11 & -0.08 & 0 & -0.01 & 0 & -0.06 & 0 \\
\hline a7 & 0.14 & 0.11 & -0.05 & 0 & 0.00 & 0 & -0.03 & 0 \\
\hline b8 & 0.1 & 0.07 & 0.06 & 0 & 0.01 & 0 & 0.00 & 0 \\
\hline a8 & 0.1 & 0.07 & 0.02 & 0.02 & 0.02 & 0 & 0.03 & 0 \\
\hline b9 & 0.08 & 0.07 & 0.04 & 0 & 0.001 & 0 & 0.00 & 0 \\
\hline a9 & 0.08 & 0.07 & 0.01 & 0 & -0.01 & 0 & 0.01 & 0 \\
\hline b10 & 0.06 & 0.03 & -0.10 & -0.14 & -0.1 & -0.09 & -0.04 & -0.04 \\
\hline a10 & 0.06 & 0.03 & 0.02 & 0 & 0.00 & 0 & -0.01 & 0 \\
\hline
\end{tabular}

Magnetic measurements and calculations for the as built geometry are in a good agreement for each model magnet. The result of improving coil size on field quality is directly apparent. The measurement results show that the required systematic values of field measurements in the magnet body can be achieved within the specified uncertainty with at most a small correction which is within the capability of the tuning shim design. The RMS spread of the harmonics observed for the three short models is within the specified range. A new coil end design provides for a modest improvement in the systematic errors in the magnet ends [11].

\section{CONCLUSIONS}

The Fermilab/LBNL model magnet program has made significant progress in the understanding and optimization of the cable and insulation design; splice geometry; quench protection and heater performance; field quality and tuning capability; and production quality assurance issues. The quench performance needs to improve, and the current focus of the model program is to address this issue.

In the next months we plan to complete the autopsy of magnet HGQ02 and complete the testing and analysis of HGQ03. The assembly of the next two model magnets is underway, focussed on alternative mechanical support systems. Final optimization of the magnetic design, tuning shim capability, and quench heaters and quench protection issues will continue.

\section{REFERENCES}

[1] Large Hadron Collider Conceptual Design, CERN/AC/95-05 (LHC) 1995, p.92.

[2] T. Nakamoto et al, "Ouench and Mechanical Behavior of a Insertion Quadrupole for LHC", paper LKA-03 this Conference.

[3] Y. Huang et al, "Thermal Design of a High Gradient Quadrupole for the LHC Interaction Regions", IEEE Transactions on Applied Superconductivity, Vol. 7, No. 2, June 1997, p.578.

[4] R. Byrns et al, "The Cryogenics of the LHC Interaction Region Final Focus Superconducting Magnets", presented at ICEC17, (Bournemouth) England, July 14-17, 1998.

[5] R. Bossert et al., "Fabrication of the First Short Model of a High Gradient Quadrupole for the LHC Interaction Regions", Proceedings of MT-15, Beijing (China), October 20-24 1997.

[6] J.P. Ozelis et al., "Mechanical Design and Performance of the Fermilab High Gradient Quadrupole Model Magnets for the LHC Interaction Regions", Paper LFB-03 this Conference.

[7] R. Bossert et al., "Test Results of Short Model Quadrupoles for the LHC Low- $\beta$ Insertions", Proceedings of the Sixth European Particle Accelerator Conference, Stockholm (Sweden), June 1998, p.2032.

[8] R. Bossert et al., "Quench Protection Studies of Short Model High Gradient Quadrupoles", Paper LTB-04 this Conference.

[9] R. Bossert et al., "Magnetic Measurements of the Fermilab High Gradient Quadrupoles for the LHC Interaction Regions", Paper LDC-10 this Conference.

[10] W. Chou et al., Fermilab Pub-97/378, November 1997.

[11] R. Bossert et al., "Analysis of Magnetic Measurements of Short Model Quadrupoles for the LHC Low- $\beta$ Insertions", Proceedings of the Sixth European Particle Accelerator Conference Stockholm (Sweden), June 1998, p.2029. 